\title{
Metodologia para o teste de tetrazólio em sementes de feijão-caupi
}

\author{
Methodology for tetrazolium in cowpea seeds
}

\author{
Glauce Portela De Oliveira ${ }^{1 *}$, Elisangela Clarete Camili² e Otoniel Magalhães Morais ${ }^{3}$ \\ ${ }^{1}$ Universidade Federal de Mato Grosso. Rondonópolis, Mato Grosso, Brasil \\ ${ }^{2}$ Universidade Federal de Mato Grosso, Faculdade de Agronomia e Zootecnia (FAAZ/UFMT), Departamento de Fitotecnia \\ e Fitossanidade. Cuiabá, Mato Grosso, Brasil. \\ ${ }^{3}$ Universidade Estadual do Sudoeste da Bahia, Departamento de Fitotecnia e Zootecnia (DFZ/UESB). Vitória da \\ Conquista, Bahia, Brasil.
}

\author{
*Autor para correspondência: \\ glauceoli@gmail.com \\ Conflitos de Interesse: \\ Os autores declaram não ter \\ conflito de interesse \\ Licença: \\ Creative Commons CC-BY \\ Historial: \\ Recebido: 20/02/18; \\ Aceito: $14 / 12 / 18$
}

\begin{abstract}
RESUMO
O objetivo foi determinar o método de coloração, quanto ao tempo e concentração da solução, mais eficiente para avaliação da qualidade fisiológica de sementes de feijãocaupi ( $V$. unguiculata) pelo teste de tetrazólio. Foram avaliados dois lotes de sementes de duas cultivares de feijão-caupi, BRS Guariba e BRS Novaera. O teste de tetrazólio foi realizado para sementes de cada lote e cultivar, as quais foram submetidas à solução de tetrazólio nas concentrações de $0,075 \%, 0,25 \%$ e $0,5 \%$ por 3 e 4 h, em incubadora tipo $B O D$ a $35^{\circ} \mathrm{C}$, na ausência de luz. As sementes foram avaliadas quanto à uniformidade e intensidade da coloração apresentadas pelos tecidos, sendo classificadas em: coloração fraca, coloração adequada ou coloração forte. Para avaliar a eficiência do teste de tetrazólio, as sementes das duas cultivares e os respectivos lotes foram submetidos aos testes de germinação e vigor. As médias observadas nos testes foram comparadas pelo teste de Tukey $(p<0,05)$ e calculados os coeficientes de correlação simples de Pearson (r). Observou-se que o teste de tetrazólio é eficiente para a classificação do vigor de sementes de feijão-caupi e posterior imersão em solução de tetrazólio na concentração de $0,075 \%$, por um período de $4 \mathrm{~h}$ a $35^{\circ} \mathrm{C}$.
\end{abstract}

Palavras-chave: Vigna unguiculata, viabilidade, vigor.

\begin{abstract}
The objective of this study was to determine the most efficient method for the evaluation of the physiological quality of cowpea ( $V$. unguiculata) seeds by the tetrazolium test. We evaluated two seed lots of two cowpea cultivars, BRS Guariba and BRS Novaera. The tetrazolium test was performed for each batch of seeds and cultivating, which underwent tetrazolium solution at concentrations of $0.075 \%, 0.25 \%$ and $0.5 \%$ for $3-4 \mathrm{~h}$ in $\mathrm{BOD}$ incubator at $35^{\circ} \mathrm{C}$ in absence of light. The seeds were evaluated for uniformity and intensity of color presented by the tissues, being classified as: weak staining, suitable staining or strong staining. To evaluate the efficiency of the tetrazolium test, seeds of both cultivars and their lots were submitted to the germination and vigor tests. The mean values found in the tests were compared by Tukey test $(p<0.05)$ and calculated the simple correlation coefficients of Pearson $(r)$. It was observed that the tetrazolium is effective to classify the force of cowpea seeds under subsequent immersion in tetrazolium solution at a concentration of $0.075 \%$, for a period $4 \mathrm{~h}$ at $35^{\circ} \mathrm{C}$.
\end{abstract}

Key words: Vigna unguiculata, viability, vigor.

\section{INTRODUÇÃO}

O feijão-caupi (Vigna unguiculata) é uma espécie rústica bem adaptada a diversas condições de clima e solo com grande variabilidade genética, o que a torna versátil, podendo ser usada em diferentes sistemas de produção, tradicionais ou modernos (Freire-Filho et al. 2005).
Em 2013, o Brasil exportou 24 mil toneladas de feijão-caupi, conquistando o mercado externo nos últimos anos com produção de sementes certificadas, cujos maiores compradores foram Índia, Egito, Emirados Árabes, Arábia Saudita, Irã e Indonésia (EMBRAPA 2014, Teixeira et al. 2010). 
No segmento de produção, a tecnologia de sementes tem procurado melhorar os testes de vigor com o objetivo de aprimorar a estimativa do potencial desempenho de um lote de sementes em campo (Nogueira et al. 2014). A avaliação do vigor de sementes, como rotina pela indústria sementeira, tem evoluído à medida que os testes disponíveis vêm sendo aperfeiçoados, fornecendo maior precisão e reprodutibilidade de resultados dentro e entre laboratórios (Krzyzanowski et al. 1991).

A qualidade de lotes de sementes é rotineiramente avaliada pelo teste de germinação, conduzido sob condições favoráveis de umidade, temperatura, luz e substrato, permitindo a expressão máxima do potencial de germinação (Gimenez et al. 2014).

Dentre os testes com o objetivo de avaliar a qualidade fisiológica de sementes, o ensaio de tetrazólio foi provado ser um dos métodos mais eficazes e completos. O teste baseia-se na atividade das enzimas desidrogenases, que reduz o sal de tetrazólio nos tecidos vivos das sementes. Quando a semente é imersa na solução de tetrazólio, ocorre a reação de redução nas células vivas resultando na formação de um composto vermelho, não difusível, conhecido como trifenilformazan, indicando haver atividade respiratória nas mitocôndrias e, consequentemente, que o tecido é viável (vivo). Tecidos mortos (não viáveis) não reagem com a solução conservando a sua cor natural, conforme França Neto et al. (1998).

Trata-se de um teste que, pela observação da coloração obtida nas diferentes partes da semente, permite determinar a presença, a localização e a natureza das alterações nos tecidos das sementes, permitindo ainda identificar, muitas vezes, as causas da perda da viabilidade e do vigor. Além de estimar a viabilidade das sementes, o teste de tetrazólio tem se mostrado como uma alternativa interessante pela qualidade e rapidez na determinação da viabilidade e do vigor da semente, permitindo obter resultados, de modo geral, em menos de 24 horas (Costa e Marcos Filho 1994, Vieira et al. 1994). No entanto, a eficácia do teste de tetrazólio depende do desenvolvimento de uma metodologia adequada para cada espécie, e que é necessário para definir a concentração do sal de tetrazólio, o tempo e temperatura de exposição das sementes, além do corte ideal para a exposição do tecido embrionário (Bhering et al. 2005).
As recomendações das Regras para Análise de Sementes (MAPA 2009) são inespecíficas quanto à concentração da solução de tetrazólio a ser empregada, além de requerer longos períodos para a obtenção dos resultados. Esses fatores reforçam a necessidade de aperfeiçoar as recomendações para realização do teste de tetrazólio em sementes de espécies específicas (Costa e Santos 2010).

O objetivo da pesquisa foi determinar o método de coloração, quanto ao tempo e concentração da solução, mais eficiente para avaliação da qualidade fisiológica de sementes de feijão-caupi ( $V$. unguiculata) pelo teste de tetrazólio.

\section{MATERIAL E MÉTODOS}

As análises foram conduzidas no Laboratório de Sementes da Universidade Federal de Mato Grosso, em Cuiabá-MT. Foram avaliados dois lotes de sementes de duas cultivares de feijão-caupi BRS Guariba e BRS Novaera.

Um pré-teste de tetrazólio, foi executado para cada lote e cultivar, buscando determinar a concentração que melhor proporcionasse coloração uniforme e de intensidade adequada para avaliação. Quatro repetições de cinquenta sementes foram précondicionadas inteiras em papel de germinação (germitest), previamente umedecido até 2,5 vezes a massa ( $\mathrm{g}$ ) do papel com água destilada, dobrado como envelope (entre papel) e colocado dentro de sacos plásticos, para manter a umidade, por $16 \mathrm{~h} \mathrm{a}$ $25^{\circ} \mathrm{C}$, período este de pré-umedecimento opcional no pré-teste, visando reduzir o tempo do teste de tetrazólio para facilitar a rotina de avaliação nos laboratórios, uma vez que MAPA (2009), determina o pré-umedecimento por $22 \mathrm{~h}$ a $25^{\circ} \mathrm{C}$.

Para a coloração, quatro repetições de cinquenta sementes de cada um dos lotes e cultivar foram imersas em solução de tetrazólio nas concentrações de $0,075 \%, 0,25 \%$ e $0,5 \%$, em copos plásticos com capacidade para $50 \mathrm{~mL}$, por 3 e $4 \mathrm{~h}$, em incubadora tipo BOD a $30^{\circ} \mathrm{C}$, em ausência de luz. Ao término do período de coloração, as sementes foram lavadas em água corrente, cortadas longitudinalmente no centro do eixo embrionário e avaliadas quanto à uniformidade e intensidade da coloração apresentadas pelos tecidos, sendo classificadas em: coloração adequada, fraca ou forte.

A coloração adequada, consiste naquela que proporciona área da semente totalmente colorida, 
com distinção das estruturas para avaliação. Já as colorações coloração fraca ou forte não são aceitas como padronização, pois ambas não realçam e inibem a diferenciação das estruturas da semente e consequentemente impede sua análise criteriosa, atribuindo resultados errôneos à classificação da semente.

Para avaliar a eficiência do teste de tetrazólio, as sementes dos dois lotes das duas cultivares foram submetidas aos testes de germinação, envelhecimento acelerado, condutividade elétrica, emergência de plântulas em areia, comprimento, massa da matéria seca das plântulas (parte aérea e raiz).

No teste de germinação foram utilizadas quatro repetições de cinquenta sementes de cada tratamento, semeadas em substrato papel tipo germitest, umedecido com 2,5 vezes a massa e mantidas em câmara tipo BOD à temperatura de $25^{\circ} \mathrm{C}$. As avaliações foram feitas no quinto e oitavo dias após a semeadura de acordo com as Regras para Análise de Sementes (MAPA 2009).

Para a realização do teste de envelhecimento acelerado as sementes foram acondicionadas sobre tela de caixas plásticas do tipo "gerbox" para envelhecimento, distribuídas em camada única contendo $40 \mathrm{~mL}$ de água deionizada. Em seguida, as caixas foram fechadas e conduzidas à câmara sob temperatura de $42^{\circ} \mathrm{C}$, por $48 \mathrm{~h}$, procedendo-se a leituras do teste após 5 dias (Dutra e Teófilo 2007).

No teste de condutividade elétrica, utilizou-se duzentas sementes distribuídas em quatro repetições de 50, colocadas para embeber em 75 $\mathrm{mL}$ de água destilada em copos plásticos (capacidade de $200 \mathrm{~mL}$ ), durante $16 \mathrm{~h}$, a $30^{\circ} \mathrm{C}$ (Dutra et al. 2006). Após esse período foi obtida a condutividade da solução de embebição com o auxílio de um condutivímetro, sendo os resultados expressos em $\mu \mathrm{S} \mathrm{cm}^{-1} \mathrm{~g}^{-1}$ de semente.

Para o teste de emergência de plântulas, duzentas sementes de cada lote, em quatro subamostras de cinquenta, foram semeadas em bandejas plásticas contendo areia como substrato. As bandejas foram mantidas em bancadas dispostas em sala refrigerada a $25 \pm 3^{\circ} \mathrm{C}$, com $12 \mathrm{~h}$ de luz e irrigadas diariamente. Determinou-se a percentagem de plântulas emergidas aos 15 dias após a semeadura.
No teste de comprimento de plântula foram utilizadas quatro repetições de dez sementes. As sementes foram dispostas no terço superior do papel de germinação no sentido longitudinal. Foram utilizadas três folhas de papel de germinação, as quais foram umedecidas previamente com água destilada equivalente a 2,5 vezes a massa seca do papel. Os rolos foram acondicionados em sacos plásticos posicionados verticalmente em câmara $B O D$, na ausência de luz, por 5 dias a $25^{\circ} \mathrm{C}$. Ao final deste período, foi efetuada a medida das partes das plântulas normais emergidas (raiz primária e hipocótilo) utilizando-se uma régua. O comprimento médio das partes das plântulas, em cada repetição, foi obtido somando os valores tomados de cada plântula normal, e, dividindo pelo número de plântulas normais. Os resultados foram expressos em centímetros (Nakagawa 1999).

Em conjunto ao teste de comprimento de plântula, após a medida das estruturas, avaliou-se a massa da matéria seca das plântulas. Com o auxílio de um bisturi, foram removidos os cotilédones e as plântulas foram divididas em parte aérea (hipocótilo) e raiz primária. Posteriormente foram colocados em sacos de papel e, a seguir levados para secar em estufa a $80^{\circ} \mathrm{C}$, durante $24 \mathrm{~h}$. Após este período, as amostras foram retiradas da estufa e colocadas para esfriar em dessecador. Uma vez esfriadas, foram pesadas em balança com precisão de $0,001 \mathrm{~g}$ e determinada a massa da matéria seca das partes das plântulas. A massa obtida foi dividida pelo número de plântulas normais componentes, resultando na massa média de matéria seca por parte da plântula, expressa em mg plântula $^{-1}$ (Nakagawa 1999).

Para o teste de tetrazólio, dentre as metodologias do pré-teste, empregou-se aquela que proporcionou coloração adequada. Assim, 100 sementes de cada lote, em quatro subamostras de 25 sementes, foram pré-condicionadas por $16 \mathrm{~h}$, entre papel umedecido a $25^{\circ} \mathrm{C}$. Para a coloração, o teste foi conduzido com solução de tetrazólio a 0,075\%, por duas $\mathrm{h}$ a $35^{\circ} \mathrm{C}$. Após o período de coloração, as sementes foram lavadas em água corrente, seccionadas longitudinalmente no centro do eixo embrionário e analisadas sob lupa de aumento de 8x. A interpretação baseou-se na localização e intensidade de coloração dos tecidos embrionários, presença e localização de danos e, as sementes foram classificadas em viáveis vigorosas, viáveis não vigorosas e não viáveis (MAPA 2009). 
Para a classificação viáveis vigorosas, o embrião apresenta-se externa e internamente íntegro, completamente colorido (róseo brilhante a vermelho carmim). A classe viáveis não vigorosas, a extremidade da radícula e/ou dos cotilédones apresentam-se não coloridos ou inteiramente coloridos de vermelho carmim mais forte e na classe de sementes inviáveis, o embrião encontra-se completamente colorido (coloração amarelada, branco leitoso ou vermelho carmim mais forte); eixo hipocótilo-radícula e/ou ponto de inserção dos cotilédones com o ponto de crescimento apical comprometido (coloração amarelada, branco leitoso ou vermelho intenso); embrião com tecido flácido.
Os resultados foram expressos em percentual de sementes viáveis vigorosas.

As médias observadas nos testes foram comparadas pelo teste de Tukey $(p<0,05)$ e calculados os coeficientes de correlação simples de Pearson ( $r$ ).

\section{RESULTADOS E DISCUSSÃO}

A Tabela 1 apresenta o padrão de coloração das sementes de feijão-caupi imersas por diferentes tempos em soluções de tetrazólio nas concentrações de 0,075\%, 0,25\% e 0,5\%.

Tabela 1. Padrão de coloração de sementes de feijão-caupi (Vigna unguiculata) submetidas a diferentes tempos e concentrações de solução de tetrazólio.

\begin{tabular}{|c|c|c|c|c|c|c|}
\hline Cultivar & Lote & $\begin{array}{c}\text { Tempos de } \\
\text { coloração } \\
\text { (h) }\end{array}$ & $\begin{array}{l}\text { Concentrações } \\
\text { da solução (\%) }\end{array}$ & $\begin{array}{l}\text { Coloração } \\
\text { Fraca (\%) }\end{array}$ & $\begin{array}{c}\text { Coloração } \\
\text { Adequada } \\
(\%)\end{array}$ & $\begin{array}{l}\text { Coloração } \\
\text { Forte (\%) }\end{array}$ \\
\hline \multirow{12}{*}{$\begin{array}{c}\text { 'BRS } \\
\text { Guariba' }\end{array}$} & \multirow{6}{*}{1} & \multirow[t]{3}{*}{$\mathrm{C}_{2}$} & 0,075 & $87 \mathrm{Aa}$ & $13 \mathrm{Ba}$ & $0 \mathrm{Cb}$ \\
\hline & & & 0,25 & $0 \mathrm{Bb}$ & $0 \mathrm{Bb}$ & $100 \mathrm{Aa}$ \\
\hline & & & 0,5 & $0 \mathrm{Bb}$ & $0 \mathrm{Bb}$ & $100 \mathrm{Aa}$ \\
\hline & & \multirow{3}{*}{4} & 0,075 & $2 \mathrm{Ba}$ & $98 \mathrm{Aa}$ & $0 \mathrm{Cc}$ \\
\hline & & & 0,25 & $0 \mathrm{Cc}$ & $22 \mathrm{Bb}$ & $78 \mathrm{Ab}$ \\
\hline & & & 0,5 & $0 \mathrm{Bb}$ & $0 \mathrm{Bb}$ & $100 \mathrm{Aa}$ \\
\hline & \multirow{6}{*}{2} & \multirow{3}{*}{3} & 0,075 & $81 \mathrm{Aa}$ & $19 \mathrm{Ba}$ & $0 \mathrm{Cb}$ \\
\hline & & & 0,25 & $0 \mathrm{Bb}$ & $1 \mathrm{Bb}$ & $99 \mathrm{Aa}$ \\
\hline & & & 0,5 & $0 \mathrm{Bb}$ & $0 \mathrm{Bb}$ & $100 \mathrm{Aa}$ \\
\hline & & \multirow{3}{*}{4} & 0,075 & $0 \mathrm{Ba}$ & $100 \mathrm{Aa}$ & $0 \mathrm{BC}$ \\
\hline & & & 0,25 & $0 \mathrm{Ca}$ & $28 \mathrm{Bb}$ & $72 \mathrm{Ab}$ \\
\hline & & & 0,5 & $0 \mathrm{Ba}$ & $0 \mathrm{Bc}$ & $100 \mathrm{Aa}$ \\
\hline \multirow{12}{*}{$\begin{array}{c}\text { 'BRS } \\
\text { Novaera' }\end{array}$} & \multirow{6}{*}{1} & \multirow{3}{*}{3} & 0,075 & $84 \mathrm{Aa}$ & $16 \mathrm{Ba}$ & $0 \mathrm{Cb}$ \\
\hline & & & 0,25 & $0 \mathrm{Bb}$ & $0 \mathrm{Bb}$ & $100 \mathrm{Aa}$ \\
\hline & & & 0,5 & $0 \mathrm{Bb}$ & $0 \mathrm{Bb}$ & $100 \mathrm{Aa}$ \\
\hline & & \multirow{3}{*}{4} & 0,075 & $2 \mathrm{Aa}$ & $98 \mathrm{Ba}$ & $0 \mathrm{Cc}$ \\
\hline & & & 0,25 & $\mathrm{OCc}$ & $24 \mathrm{Bb}$ & $76 \mathrm{Ab}$ \\
\hline & & & 0,5 & $0 \mathrm{Bb}$ & $0 \mathrm{Bc}$ & $100 \mathrm{Aa}$ \\
\hline & \multirow{6}{*}{2} & \multirow{3}{*}{3} & 0,075 & $85 \mathrm{Aa}$ & $15 \mathrm{Ba}$ & $0 \mathrm{Cb}$ \\
\hline & & & 0,25 & $0 \mathrm{Bb}$ & $0 \mathrm{Bb}$ & $100 \mathrm{Aa}$ \\
\hline & & & 0,5 & $0 \mathrm{Bb}$ & $0 \mathrm{Bb}$ & $100 \mathrm{Aa}$ \\
\hline & & \multirow{3}{*}{4} & 0,075 & $1 \mathrm{Ba}$ & $99 \mathrm{Aa}$ & $0 \mathrm{BC}$ \\
\hline & & & 0,25 & $\mathrm{OCb}$ & $22 \mathrm{Bb}$ & $78 \mathrm{Ab}$ \\
\hline & & & 0,5 & $0 \mathrm{Bb}$ & $0 \mathrm{Bc}$ & $100 \mathrm{Aa}$ \\
\hline CV (\%) & & & & & & \\
\hline
\end{tabular}

*Médias seguidas pela mesma letra maiúscula na linha e minúscula na coluna, não diferem entre si pelo teste de Tukey $(p<0,05)$.

A classificação das sementes permitiu determinar o melhor tempo e concentração de tetrazólio para coloração de sementes de feijão-caupi (Figura 1).

Verificou-se que os melhores resultados para a coloração destas sementes foram obtidos para os dois lotes das duas cultivares quando as sementes foram submetidas à solução de tetrazólio na concentração de $0,075 \%$ por $4 \mathrm{~h}$. Tais resultados contradizem as recomendações das Regras para Análise de Sementes (MAPA 2009), que indicam concentrações de 0,5 a $1,0 \%$ da solução de tetrazólio e períodos de coloração de 16 a 24 h. Deste modo, a indicação da solução a 0,075\%, contribui ainda para a redução de custos das análises. 
As demais concentrações testadas proporcionaram colorações muito fortes, dificultando a classificação das sementes, tanto com 3 ou $4 \mathrm{~h}$ de imersão na solução de tetrazólio. Resultado contrário e também inadequado foi obtido quando as sementes foram mantidas na solução de tetrazólio a 0,075\% por 3 h, quando se obteve coloração fraca, não permitindo o realce das estruturas da semente e consequentemente sua análise criteriosa, o que fundamenta o teste.

Costa e Santos (2010) testando as concentrações de $0,075 \%, 0,15 \%$ e $1 \%$ observaram que as concentrações mais baixas foram os mais eficazes na coloração de sementes de leucena (Leucaena leucocephala), enquanto que a utilização da concentração de $1 \%$ dificultou a interpretação dos resultados, devido à coloração intensa de tecidos, corroborando com os resultados obtidos neste estudo com sementes de feijão-caupi.

Giménez et al. (2014) obtiveram respostas satisfatórias em sementes de Annona cherimola com a concentração mais elevada de tetrazólio (1\%) em 2 h de exposição.

No entanto, houve uma alta porcentagem de sementes viáveis quando menores concentrações de sal $(0,05 \%$ e $0,5 \%)$ foram usadas por períodos de exposição mais longos, por $6 \mathrm{~h}$.

Para Abbade e Takaki (2014) o précondicionamento das sementes e a utilização de uma solução de diferentes concentrações de tetrazólio combinados ao tempo de coloração e temperatura, são medidas cruciais para garantir boa interpretação e testes bem-sucedidos.

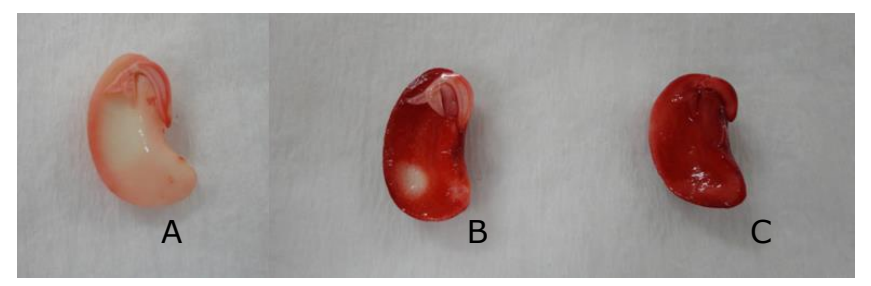

Figura 1. Sementes de feijão-caupi (Vigna unguiculata) submetidas à coloração em solução de tetrazólio nas concentrações de $0,075 \%(A), 0,25 \%(B)$ e $0,5 \%(C)$, por $4 \mathrm{~h}$.

Na Tabela 2 são apresentados os resultados do teste padrão de germinação, envelhecimento acelerado, tetrazólio e emergência de plântulas em areia. Verifica-se pelos dados de porcentagem de germinação que todos os lotes apresentavam o mesmo padrão de qualidade. No entanto, quando submetidos aos testes de vigor, o envelhecimento acelerado possibilitou distinguir a qualidade dos dois lotes da cultivar BRS Novaera e, o tetrazólio separou por níveis de vigor tanto os lotes da 'BRS Novaera' como da 'BRS Guariba'.

O teste de tetrazólio permitiu discriminar os lotes por meio do vigor dos mesmos (Tabela 2). O lote 2 das duas cultivares apresentou resultados superiores aos encontrados para o lote 1 quando as sementes foram submetidas ao teste de tetrazólio.

Para Costa e Santos (2010), o teste de tetrazólio é eficaz em relação à estimativa da viabilidade das sementes, quanto à separação dos lotes em níveis de qualidade fisiológica para sementes de leucena. Os estudos confirmam a possibilidade de utilização do teste de tetrazólio para avaliar a viabilidade das sementes, conforme já observado em diversas espécies, como Poecilanthe parviflora (Pinto et al. 2008), Erythrina velutina (Bento et al. 2010), Melanoxylon brauna (Corte et al. 2010), Ricinus communis (Gaspar-Oliveira et al. 2011) e ainda Eugenia involucrata e Eugenia pyriformis (Cripa et al. 2014).

A avaliação comprimento de raiz de plântulas (CPRA) permitiu a diferenciação de lotes das cultivares BRS Guariba e BRS Novaera. Já o comprimento da parte aérea de plântulas (CRA) e o teste de condutividade elétrica foram eficientes, ainda, para a distinção de lotes somente da cultivar BRS Novaera.

As variáveis massa de matéria seca de parte aérea (MSPA) e massa de matéria seca de raiz (MSRA) de plântulas, não apresentaram diferença na avaliação de lotes das duas cultivares. Os resultados referentes à viabilidade das sementes, pelo teste de tetrazólio em concentração de $0,075 \%$ por $4 \mathrm{~h}$, 
diferiram e foram inferiores aos resultados dos testes de germinação das sementes e vigor (envelhecimento acelerado e emergência em areia). Deste modo, em conjunto com o teste de comprimento de plântulas, o tetrazólio permitiu a diferenciação do vigor de lotes das cultivares, permitindo recomendá-lo como avaliação confiável e complementar ao teste de germinação para avaliação da qualidade fisiológica das sementes e comparação de lotes comerciais.

Resultados semelhantes foram relatados por Kaiser et al. (2014), que avaliando sementes de $E$. uniflora, determinaram que o teste de tetrazólio é um método rápido e confiável para estimar a viabilidade de sementes, permitindo utilizá-lo como complementar ao teste de germinação.

Nas Tabelas 4 e 5 estão apresentados os coeficientes de correlação de Pearson entre as variáveis germinação, envelhecimento acelerado, emergência, tetrazólio e condutividade elétrica, para as cultivares BRS Guariba e BRS Novaera, respectivamente. Todas as variáveis descritas nas tabelas apresentaram correlações significativas $(p<0,05)$.

Os coeficientes de correlação de Pearson obtidos para as cultivares BRS Guariba (Tabela 4) e BRS Novaera (Tabela 5) confirmam a eficiência do teste de tetrazólio como indicativo do vigor de sementes de feijão-caupi, indicando que o aumento na viabilidade corresponde diretamente ao aumento da germinação e vigor. Os índices de correlações negativas apresentados relacionam-se à condutividade elétrica da solução na qual foram submetidas as sementes ao teste.

Pelo teste de condutividade elétrica, as sementes que apresentam menor lixiviação de solutos e, consequentemente, menor valor de condutividade elétrica, são as mais vigorosas, portanto, apresentam correlação negativa com os demais testes (Schuab et al. 2006).

Tabela 2. Germinação (GER), envelhecimento acelerado (EA), condutividade elétrica (CE), tetrazólio (TZ) e emergência em areia (EMER) de sementes de duas cultivares de feijão-caupi (Vigna unguiculata)

\begin{tabular}{cccccc}
\hline Cultivar & Lote & GER (\%) & EA (\%) & TZ (\%) & EMER (\%) \\
\hline 'BRS Guariba' & 1 & $95 \mathrm{~A}$ & $94 \mathrm{~A}$ & $97 \mathrm{~B}$ & $95 \mathrm{~A}$ \\
& 2 & $94 \mathrm{~A}$ & $90 \mathrm{~A}$ & $85 \mathrm{~A}$ & $95 \mathrm{~A}$ \\
\hline 'BRS Novaera' & 1 & $97 \mathrm{~A}$ & $96 \mathrm{~B}$ & $95 \mathrm{~B}$ & $93 \mathrm{~A}$ \\
& 2 & $94 \mathrm{~A}$ & $86 \mathrm{~A}$ & $88 \mathrm{~A}$ & $94 \mathrm{~A}$ \\
\hline CV (\%) & & & $\mathbf{7 , 3 1}$ &
\end{tabular}

*Médias seguidas pela mesma letra, maiúscula nas colunas e, em cada cultivar e lote, não diferem entre si pelo teste de Tukey $(p<0,05)$.

Tabela 3. Dados médios de condutividade elétrica (CE), comprimento da parte aérea (CPA), comprimento de raiz (CRA), massa da matéria seca da parte aérea (MSPA) e massa da matéria seca de raiz (MSRA) de plântulas originadas a partir de sementes de duas cultivares de feijão-caupi (Vigna unguiculata).

\begin{tabular}{ccccccc}
\hline Cultivar & Lote & $\begin{array}{c}\text { CE } \\
\left(\boldsymbol{\mu} \mathbf{~} \mathbf{~ c m ~ ~ ^ { - 1 }}\right)\end{array}$ & $\begin{array}{c}\text { CPA } \\
(\mathbf{c m})\end{array}$ & $\begin{array}{c}\text { CRA } \\
(\mathbf{c m})\end{array}$ & $\begin{array}{c}\text { MSPA } \\
(\mathbf{m g})\end{array}$ & $\begin{array}{c}\text { MSRA } \\
(\mathbf{m g})\end{array}$ \\
\hline \multirow{2}{*}{ 'BRS Guariba' } & 1 & $1508,64 \mathrm{~A}$ & $3,5^{\mathrm{a}}$ & $6,33 \mathrm{~B}$ & $4,46 \mathrm{~A}$ & $4,45 \mathrm{~A}$ \\
& 2 & $1463,91 \mathrm{~A}$ & $3,72^{\mathrm{a}}$ & $6,62 \mathrm{~A}$ & $4,47 \mathrm{~A}$ & $4,45 \mathrm{~A}$ \\
\hline \multirow{2}{*}{ 'BRS Novaera' } & 1 & $1767,70 \mathrm{~A}$ & $4,19^{\mathrm{a}}$ & $5,90 \mathrm{~B}$ & $4,47 \mathrm{~A}$ & $4,46 \mathrm{~A}$ \\
& 2 & $1908,97 \mathrm{~B}$ & $4,68 \mathrm{~B}$ & $8,27 \mathrm{~A}$ & $4,48 \mathrm{~A}$ & $4,46 \mathrm{~A}$ \\
\hline
\end{tabular}

CV (\%) $\mathbf{7 , 3 1}$

*Médias seguidas pela mesma letra, maiúscula nas colunas e, em cada cultivar e lote, não diferem entre si pelo teste de Tukey ( $\mathrm{p}<0,05)$. 
Tabela 4. Coeficientes de correlação de Pearson ( $r$ ) estimados entre os testes de germinação (GER), envelhecimento acelerado (EA), emergência (EMER), tetrazólio (TZ) e condutividade elétrica (CE) em sementes de feijão-caupi (Vigna unguiculata) cultivar BRS Guariba

\begin{tabular}{cccccc}
\hline & GER & EA & EMER & TZ & CE \\
GER & 1 & $0,9456^{*}$ & $0,9052^{*}$ & $0,8712^{*}$ & $-0,9583^{*}$ \\
EA & & 1 & $0,8956 *$ & $0,8537^{*}$ & $-0,8946^{*}$ \\
EMER & & 1 & $0,8830 *$ & $-0,9574^{*}$ \\
TZ & & & 1 & $-0,9687^{*}$ \\
CE & & & & 1 \\
\hline
\end{tabular}

*Significativo ao nível de $5 \%$ de probabilidade pelo teste $\mathrm{F}(\mathrm{P}<0,05)$.

Tabela 5. Coeficientes de correlação de Pearson ( $r$ ) estimados entre os testes de germinação (GER), envelhecimento acelerado (EA), emergência (EMER), tetrazólio (TZ) e condutividade elétrica (CE) em sementes de feijão-caupi (Vigna unguiculata) cultivar BRS Novaera

\begin{tabular}{|c|c|c|c|c|c|}
\hline & GER & EA & EMER & TZ & CE \\
\hline GER & 1 & $0,9102 *$ & $0,9847 *$ & $0,8220 *$ & $-0,9673 *$ \\
\hline EA & & 1 & $0,9707 *$ & 0,8209* & $-0,9415^{*}$ \\
\hline EMER & & & 1 & $0,8162 *$ & $-0,5658 *$ \\
\hline TZ & & & & 1 & $-0,9067^{*}$ \\
\hline CE & & & & & 1 \\
\hline
\end{tabular}

*Significativo ao nível de $5 \%$ de probabilidade pelo teste $\mathrm{F}(\mathrm{P}<0,05)$.

\section{CONCLUSÕES}

O método mais adequado para avaliação da viabilidade de sementes de feijão-caupi pelo teste de tetrazólio é o pré-condicionamento entre papel por $16 \mathrm{~h}$ a $25^{\circ} \mathrm{C}$ e posterior imersão em solução de tetrazólio na concentração de 0,075\%, por um período de $4 \mathrm{~h}$ a $35^{\circ} \mathrm{C}$.

O teste de tetrazólio é eficiente para a classificação da viabilidade de sementes de feijão-caupi.

\section{REFERÊNCIAS BIBLIOGRÁFICAS}

Abbade, LC; Takaki, M. 2014. Teste de tetrazólio para avaliação da qualidade de sementes de Tabebuia roseo-alba (Ridl.) Sandwith Bignoniaceae, submetidas ao armazenamento. Rev. Árvore 38:233-240.

Bento, SRSO; dos Santos, AEO; de Melo, DRM; Torres, SB. 2010. Eficiência dos testes de vigor na avaliação da qualidade fisiológica de sementes de mulungu (Erythrina Velutina Willd.). Revista Brasileira de Sementes. 32 (4): 111-117.
Bhering, MC; Dias, DCFS; Barros, DI. 2005. Adequação da metodologia do teste de tetrazólio para avaliação da qualidade fisiológica de sementes de melancia. Revista Brasileira de sementes 27(1):176-182.

Costa, NP; Marcos Filho, J. 1994. O emprego do teste de tetrazólio na avaliação da qualidade da semente de soja. Informativo ABRATES $4(2): 53-62$.

Costa, CJ; Santos, CP. 2010. Teste de tetrazólio em sementes de leucena. Revista Brasileira de Sementes 32(2):66-72.

Corte, VB; Borges, EEL; Pereira, BLC. 2010. Adequação da metodologia do teste de tetrazólio para avaliação da viabilidade de sementes de Melanoxylon brauna Schot. Cerne.16 (3): 415-421.

Cripa, FB; Freitas, LCN; Grings, AC; Bortolini, MF. 2014. Tetrazolium test for viability estimation of Eugenia involucrate and Eugenia pyriformis Cambess seeds. Journal Seed Science 36(3):305-311. 
Dutra, AS; Medeiros Filho, S; Teófilo, EM. 2006. Condutividade elétrica em sementes de feijão caupi. Revista Ciência Agronômica 37(2):166170.

Dutra, AS; Teófilo, EM. 2007. Envelhecimento acelerado para avaliar o vigor de sementes de feijão caupi. Revista Brasileira de Sementes 29(1):193-197.

EMBRAPA (Empresa Brasileira de Pesquisa Agropecuária, Brasília). 2014. Feijão-caupi conquista mercado internacional. Brasília, Brasil. Acesso em: 14 nov. 2014. Disponível em: https://www.embrapa.br/busca-de-noticias//noticia/2006738/feijao-caupi-conquistamercado-internacional

França Neto, JB; Krzyzanowski, FC; da Costa, NP. 1998. O teste de tetrazólio em sementes de soja. Londrina, PR: EMBRAPA- CNPSo. 72 p.

Freire Filho, FR; Lima, JAA; Ribeiro, VQ. 2005. Feijão-caupi: avanços tecnológicos. Brasília, DF: Embrapa Informação Tecnológica. 519 p.

Gaspar-Oliveira, CM; Martins, CC; Nakagawa, J. 2011. Pré-condicionamento das sementes de mamoneira para o teste de tetrazólio. Acta Scientiarum 33(2):303-311.

Gimenez, JI; Ferreira, G; Cavariani, C. 2014. Tetrazolium test for assessment of seed viability of atemoya (Annona cherimola Mill. $x$ A. squamosa L.). Journal Seed Science 36(3):357361.

Kaiser, DK; Freitas, LCN; Biron, RP; Simonato, SC; Bortolini, MF. 2014. Adjustment of the methodology of the tetrazolium test for estimating viability of Eugenia uniflora L. seeds during storage. Journal Seed Science 36(3):344-351
Krzyzanowski, FC; França Neto, JB; Henning, AA. 1991. Relato dos testes de vigor disponíveis para as grandes culturas. Informativo ABRATES 1(2):15-59.

MAPA (Ministério da Agricultura, Pecuária e Abastecimento, Brasília). 2009. Regras para análise de sementes. Brasília, Brasil: MAPA/ACS. 395 p. 2 v.

Nakagawa, J. 1999. Vigor em sementes: conceitos e testes: Testes de vigor baseados na avaliação das plântulas. Londrina, PR: ABRATES. 164 p.

Nogueira, NW; Freitas, RMO; Torres, SB; Leal, CCP. 2014. Physiological maturation of cowpea seeds. Journal Seed Science 36(3): 312-317.

Pinto, TLF; Brancalion, PHS; Novembre, ADLC; CICERO, SM. 2008. Avaliação da viabilidade de sementes de coração-de-negro (poecilanthe parviflora benth. - fabaceae-faboideae) pelo teste de tetrazólio. Revista Brasileira de Sementes 30(1):208-214.

Schuab, SRP; Braccini, AL; França Neto, JB; Scapim, CA; Meschede, DK. 2006. Potencial fisiológico de sementes de soja e sua relação com a emergência das plântulas em campo. Acta Scientiarum Agronomy 28(4):553-561.

Teixeira, IR; Silva, GC; Oliveira, JPR; Silva, AG; Pelá, A. 2010. Desempenho agronômico e qualidade de sementes de cultivares de feijãocaupi na região do cerrado. Revista Ciência Agronômica 41(2): 300-307.

Vieira, RD; Carvalho, NM; Sader, R. 1994. Teste de vigor em sementes: Teste de vigor e suas possibilidades de uso. 2 ed. Jaboticabal, PR: FUNEP/UNESP. $164 \mathrm{p}$. 